\title{
ASSOCIATION OF DIETARY SUPPLEMENTS AND MENTAL TRAINING WITH PERFORMANCE IN ROAD RACES
}

\author{
Vinícius Nagy Soares ${ }^{1 \mathrm{i}}$, \\ Gabriela Kaiser Fullin Castanho², \\ José Vitor Vieira Salgado ${ }^{3}$, \\ Paula Teixeira Fernandes ${ }^{4}$ \\ ${ }^{1}$ State University of Campinas (UNICAMP), \\ Graduate Program in Gerontology, Faculty of Medical Sciences, \\ Group of Studies in Sport Psychology and Neurosciences (GEPEN), \\ Campinas, São Paulo, Brazil \\ ${ }^{2}$ State University of Campinas (UNICAMP), \\ Faculty of Physical Education, \\ Group of Studies in Sport Psychology and Neurosciences (GEPEN), \\ Campinas, São Paulo, Brazil \\ ${ }^{3}$ State University of Campinas (UNICAMP), \\ Faculty of Physical Education, \\ Campinas, São Paulo, Brazil \\ Minas Gerais State University (UEMG), Faculty Divinópolis, \\ Physical Education, Bachelor's Degree/Licentiate \\ Divinópolis, Minas Gerais, Brazil \\ ${ }^{4}$ State University of Campinas (UNICAMP), \\ Graduate Program in Gerontology, Faculty of Medical Sciences, \\ Department of Sports Sciences, Faculty of Physical Education, \\ Group of Studies in Sport Psychology and Neurosciences (GEPEN), \\ Campinas, São Paulo, Brazil
}

\begin{abstract}
:
This study aimed to describe the psychological and nutritional aspects of runners and identify the association of mental training and dietary supplements with performance in road races. For this, a cross-sectional study was performed with 560 recreational runners, who participated in 2014 or 2015 Unicamp Running. The participants answered a Google Docs questionnaire about personal, emotional and nutritional aspects. A sub-sample of 302 runners was monitored using chip technology to identify the running time in $5 \mathrm{~km}$ and $10 \mathrm{~km}$. The main motivations for the run were to improve health (73\%), well-being $(62,5 \%)$ and quality of life (57\%). Approximately $34 \%$ consumed dietary supplements, among which $70.5 \%$ consumed proteins and $40.2 \%$ carbohydrates. The main motivations for this consumption were increased competitiveness (62.1\%) and health (46.3\%). There
\end{abstract}

i Correspondence: email viniciusnagy@gmail.com 
was no association between the consumption of dietary supplements and performance in road races. The participants who did mental training presented 2.5 to 2.3 times higher chance of better performance compared to the participants who did not do mental training ( $\mathrm{p}=0.020$ and 0.039 , respectively). We hypothesized that dietary supplementation without nutritional follow-up does not offer sporting advantage and that mental training is associated with better performance in recreational runners.

Keywords: sport psychology, nutritional supplements, running.

\section{Introduction}

In recent years, there has been increase in the number of runners around the world. Data from the Sporting Habits Survey in Spain reveal prevalence of running in approximately $30 \%$ of physically active people (Ministerio de Educación, Cultura y Deporte, 2015). The increase of runners can be perceived through Strava ${ }^{\circledR}$, a social network focused on practitioners of sports such as running, cycling and swimming. In Brazil, there are more than 4.5 million users and 1.4 million races were registered in 2018, an increase of $94.6 \%$ compared to last year (Strava, 2018). Although runners are increasing in the Brazilian population, there is no characterization about their profile, resulting in a lack of knowledge about the psychological and nutritional behaviour of road races practitioners.

\section{Literature Review}

We performed a brief research on PubMed with the synonyms of running and mental training and found only 4 studies published in the last decade (Bales and Bales, 2012; Bühlmayer et al., 2017; Dolan et al., 2011; Houston et al., 2011). These studies were conducted with adjacent sports, consisting in isolated and non-generalizable findings for road races. In this sense, mental training has been widely used to maintain an optimal level of performance in triathlon (Bales and Bales, 2012; Dolan et al., 2011; Houston et al., 2011). A meta-analysis of 9 clinical trials totalling 290 athletes from different sports observed positive effect of mindfulness in shooting and dart throwing (Bühlmayer et al., 2017). Increasing the search period to 20 years, the combination of conventional exercises and mental training has proven to be more effective than isolated physical training in swimming (Bar-Eli and Blumenstein, 2004).

Another subject of interest concerns the prevalence of consumption of dietary supplements in recreational athletes. In the past, vitamins and minerals were supplemented to cure deficiencies and prevent chronic diseases. In recent years, there has been increase in consumption of dietary supplements without people being undernourished (Lentjes, 2019). The need of supplementation can be identified through biomarkers, but many people do not have medical and nutritional follow-up. In this sense, a cross-sectional study involving 527 Spanish athletes identified a prevalence of 
supplementation in $74 \%$ of the sample, among which $42 \%$ were supplemented without consulting any professional (Baltazar-Martins et al., 2019).

It has been demonstrated that the consumption of different nutrients is associated with improved performance in endurance sports (Southward et al., 2018), intermittent exercises (Baker et al., 2015) and strength training (Morton et al., 2018). Influenced by these scientific findings, numerous dietary supplements have been introduced in retail with the promise different benefits. The problem is that ingestion does not always satisfy a real body demand, and it is common to find people ingesting substances on their own (Baltazar-Martins et al., 2019). A study involving Brazilian runners identified that the main motivations for their consumption were to increase stamina and performance (Salgado et al., 2014). Therefore, considering that increased competitiveness is an expected outcome among consumers, could the dietary supplements offer an advantage compared to those they do not consume?

To answer these gaps, this study aimed to: (i) describe the psychological and nutritional aspects of runners and (ii) identify the association of mental training and dietary supplements with performance in road races.

\section{Material and Methods}

All participants who registered for the 2014 and 2015 Volta da Unicamp (i.e., Unicamp Running) were invited to this cross-sectional study. The invitation, objectives and ethical aspects were presented in a virtual address, available at the same place of registration for the sporting event. As selection criteria, participants should be at least 18 years old and registered at Unicamp Running. The flowchart of cross-sectional study is shown in Figure 1. This study was approved by the Research Ethics Committee of the University of Campinas, São Paulo, Brazil (CAAE: 43823915.1.0000.5404).

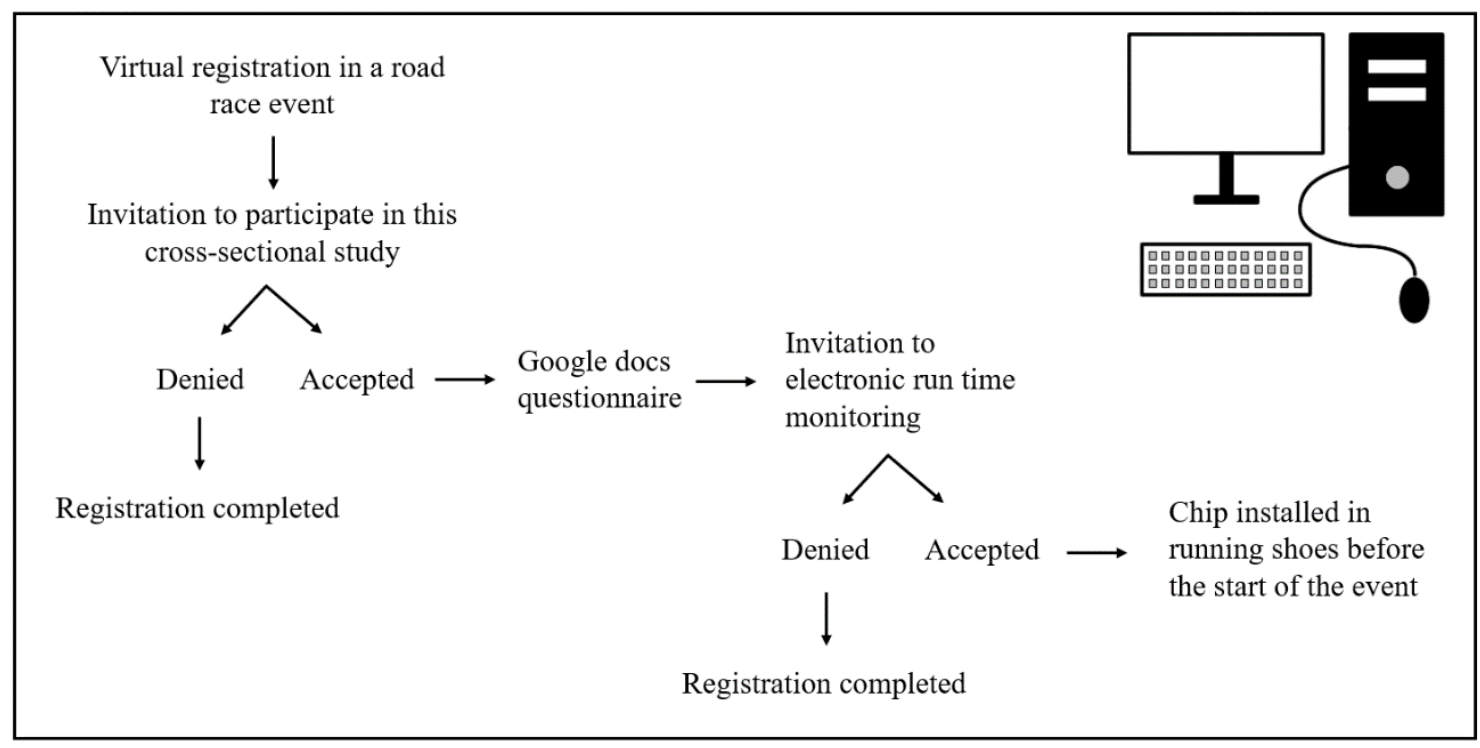

Figure 1: Flowchart of cross-sectional study 
A sample of 560 adults showed interest in answering a virtual questionnaire, and a sub-sample of 304 participants showed interest in electronic run time monitoring. The demographic characteristics are shown in Table 1.

Table 1: Characteristics of sample of road race practitioners

\begin{tabular}{lcc}
\hline Variables & $\mathbf{N}$ & $\mathbf{\%}$ \\
\hline Men & 360 & 63,7 \\
Age (mean, SD) & 32,3 & 6,4 \\
Schooling & & \\
High school degree & 36 & 8,4 \\
Undergraduate incomplete & 59 & 13,8 \\
Undergraduate degree & 137 & 32,1 \\
Graduate & 190 & 44,5 \\
Filiation & & \\
Unicamp & 174 & 42,8 \\
Other & 232 & 57,2 \\
Career at Unicamp & & \\
Employee & 52 & 31,3 \\
Student & 95 & 57,2 \\
Teacher & 19 & 11,4 \\
Road race categories of monitored participants & & \\
5km & 155 & 51,0 \\
$10 \mathrm{~km}$ & 149 & 49,0 \\
\hline
\end{tabular}

$\mathrm{SD}=$ standard deviation

\subsection{Road race}

Unicamp Running is a road race that had its first edition in 2010. This is an annual event of the State University of Campinas, in which participants run $5 \mathrm{~km}$ or $10 \mathrm{~km}$ in a circuit through the streets of the university.

\subsection{Virtual questionnaire}

To identify personal, emotional and nutritional aspects, the Google Docs questionnaire based on an instrument validated by Salgado et al. (2014) was adopted, which followed the recommendations of Foddy (1994). In this virtual questionnaire, participants answered personal identification, category $(5 \mathrm{~km}$ or $10 \mathrm{~km})$, motivation to run, mental training, self-perception of quality of life after having started running, level of precompetition anxiety, musical listening in training and/or competition, dietary supplements containing types and motivations for their consumption.

\subsection{Running time}

Participants who declared interest in electronic monitoring attended a booth to install the chip (Alien ${ }^{\circledR}$ Rfid) in their running shoes. The registration was done by passing the ramps (i.e. reading mats) attached to the start and end locations, automatically recording the running time. Participants who showed interest in walking did not have the option of electronic monitoring. The installation of the chip and the export of the data to the 
electronic spreadsheet were performed by the researchers of this study, who had experience in the electronic running time monitoring.

\subsection{Statistical analysis}

Measures of central tendency were used to characterize the variables. The Shapiro-Wilks test was used to verify if the continuous variables had normal distribution. Running time was classified as a binary variable according to the median adjusted by sex and type of road race. In this sense, the cut-off points of $5 \mathrm{~km}$ were 28.1 minutes for men and 32.9 minutes for women. In the $10 \mathrm{~km}$, the cut-off points were 53.8 and 61.4 minutes for men and women, respectively. To verify the association of mental training and dietary supplementation with the best performances in road race, binary logistic models were performed. Initially, we carried out univariate analyses and then adjusted models for possible confounders. The mental training was adjusted by the motivation to run and the level of anxiety before the event. The dietary supplement was adjusted by the type and the motivation for its consumption. The analyses modelled the category below the median (i.e., better performance), considering the category above the median as a reference (i.e., worse performance). The level of statistical significance was 5\%.

\section{Results}

The psychological and nutritional aspects of all participants are in the Table 2. About the motivations for running, the most prevalent responses were related to improve health, well-being and quality of life. Almost all participants reported an improvement in quality of life through the run and approximately half of the sample reported moderate or high level of anxiety before Unicamp Running. Approximately 1 in 6 participants did mental training and there was low prevalence for psychological support. Among those who did psychological follow-up, 93\% evaluated the support received with positive adjectives, such as "great", "essential" and "important", one participant answered "indifferent" and other answered that it was a "psychiatric indication". Half of the sample trained or competed with musical listening. Approximately 1 in 3 participants had consumed dietary supplements, specially proteins and carbohydrates. The most consumed proteins were Whey Protein, Creatine, BCAA, Glutamine and Casein. The main carbohydrates were Maltodextrin, Waxy Maize and Dextrose. The major motivations for its consumption were increased competitiveness and health.

Table 2: Psychological and nutritional aspects of road races

\begin{tabular}{|c|c|c|}
\hline Variables & $\mathbf{N}$ & $\%$ \\
\hline \multicolumn{3}{|c|}{ Motivation for running practice +} \\
\hline Aesthetics & 189 & 33,5 \\
\hline Competitiveness & 50 & 8,8 \\
\hline Decreased stress & 263 & 46,5 \\
\hline Health & 413 & 73,1 \\
\hline Individual activity & 159 & 28,1 \\
\hline
\end{tabular}




\begin{tabular}{lcc}
\hline Personal Achievement & 204 & 36,1 \\
Quality of life & 322 & 57,0 \\
Socialization & 123 & 21,8 \\
Well-being & 353 & 62,5 \\
Quality of life after running practice & & \\
$\quad$ Improved & 537 & 98,4 \\
Anxiety level pre-competition & & \\
$\quad$ Do not feel & 91 & 16,6 \\
Low & 188 & 34,4 \\
Moderate & 212 & 38,8 \\
High & 56 & 10,2 \\
Mental training & & \\
Yes & 78 & 14,6 \\
Psychological support & & \\
Yes & 29 & 5,3 \\
Musical listening & & \\
Yes & 193 & 47,0 \\
Consumption of dietary supplements & & \\
Yes & 190 & 34,2 \\
Types of dietary supplements (n=190) + & & \\
Carbohydrates & 80 & 42,1 \\
Herbal medicines & 10 & 5,3 \\
Hypercaloric & 9 & 4,7 \\
Proteins & 134 & 70,5 \\
Vitamins & 62 & 32,6 \\
Motivation for consumption of dietary supplements (n=190) + & & \\
Aesthetics & 39 & 20,5 \\
Competitiveness & 118 & 62,1 \\
Health & 88 & 46,3 \\
Palatability & 9,7 \\
\hline
\end{tabular}

$+=$ participants have chosen more than one option.

Two participants did not attend the booth to install the chip, reducing the sub-sample submitted to electronic monitoring to 302 volunteers. The run of $5 \mathrm{~km}$ was completed in mean time of $30.1 \pm 6.3$ minutes, and the $10 \mathrm{~km}$ was completed in $56.0 \pm 7.8$ minutes. The demographic characteristics were equivalent to the total sample and shown are in the Table 3. It is important to emphasize that among those who did mental training, only $12 \%$ received psychological support.

Table 3: Psychological and nutritional aspects of sub-sample submitted to electronic running time monitoring

\begin{tabular}{lcc}
\hline Variables & $\mathbf{N}$ & $\mathbf{\%}$ \\
\hline Motivation for running practice + & & \\
Aesthetics & 104 & 34,4 \\
Competitiveness & 25 & 8,3 \\
Decreased stress & 140 & 46,4 \\
Health & 223 & 73,8 \\
Individual activity & 87 & 28,8
\end{tabular}




\begin{tabular}{lcc}
\hline Personal Achievement & 104 & 34,4 \\
Quality of life & 163 & 54,0 \\
Socialization & 53 & 17,5 \\
Well-being & 186 & 61,6 \\
Quality of life after running practice & & \\
$\quad$ Improved & 285 & 98,6 \\
Anxiety level pre-competition & & \\
Do not feel & 43 & 14,8 \\
Low & 106 & 36,4 \\
Moderate & 114 & 39,2 \\
High & 28 & 9,6 \\
Mental training & & \\
Yes & 33 & 11,7 \\
Psychological support & & \\
Yes & 12 & 4,1 \\
Musical listening & & \\
Yes & 193 & 47,0 \\
Consumption of dietary supplements & & \\
Yes & 100 & 33,9 \\
Types of dietary supplements (n=100) + & & \\
Carbohydrates & 43 & 43,0 \\
Herbal medicines & 5 & 5,0 \\
Hypercaloric & 4 & 4,0 \\
Proteins & 83 & 83,0 \\
Vitamins & 30 & 30,0 \\
Motivation for consumption of dietary supplements (n=100) + & & \\
Aesthetics & 25 & 25,0 \\
Competitiveness & 67 & 67,0 \\
Health & 48 & 48,0 \\
Palatability & 3 & 3,0 \\
\hline
\end{tabular}

$+=$ participants have chosen more than one option.

The associations of mental training and consumption of dietary supplements with performance in road race are in the Figure 2. In the univariate analysis, the participants who did mental training presented 2.5 times higher chance of better performance compared to the participants who did not do mental training $(\mathrm{p}=0.020)$. This association remained in the model adjusted by the motivation to run and the level of pre-competition anxiety, in which the odds ratio was 2.3 ( $\mathrm{p}=0.039)$. The consumption of dietary supplements was not associated with the running time in univariate analysis $(p=0.130)$ and in the model adjusted by the type of supplement and the motivation for its consumption $(\mathrm{p}=0.209)$. 


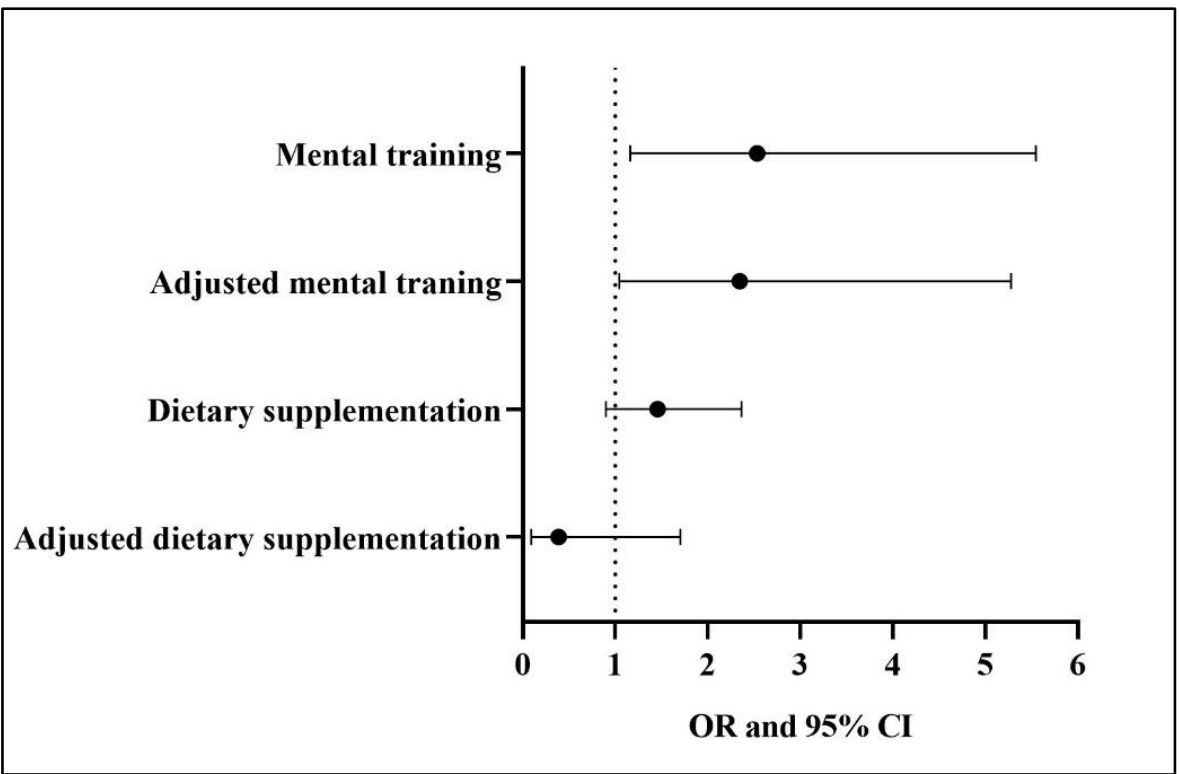

Figure 2: Association of mental training and consumption of dietary supplements with performance in road race. Results presented in Odds ratio (OR) and 95\% Confidence Interval (CI)

\section{Discussion}

We characterized psychological and nutritional aspects of recreational runners and identified that mental training can be associated with better performance in road races. In addition, the consumption of dietary supplements was not associated with the running time in Unicamp Running.

\subsection{Psychological and nutritional aspects}

The most prevalent motivations were health, well-being and quality of life. Similar results were found in The State of Running 2019, the world's largest mapping of nonprofessional running athletes (Andersen, 2020). In this study, more than 70 thousand running events that occurred between 1986 and 2018 were analysed, whose main motivations were improvement of psychological aspects, health and socialization. We believe that these results can be influenced by the characteristics of road races, because there is no specific competitor, and the reference of performance is the individual himself. Almost all participants reported an improvement in quality of life through road races, consisting in an expected result. Although the studies about quality of life are directed to specific populations, such as elderly (Cassiano et al., 2020) and people with neurological diseases (Dauwan et al., 2019), the benefits of physical exercise are consolidated in the scientific literature.

There was a higher prevalence of moderate and high level of anxiety in our sample, which should be interpreted sparingly. First because the anxiety was evaluated through a simple question instead of scales already validated. And especially because the questionnaire was answered at the moment of registration for the race event. It is possible 
that the first participants had a lower level of anxiety compared to the last ones registered. It is important to emphasize that approximately 20 days elapsed between the last registration and the race. Consequently, the estimate of pre-competition anxiety was imprecise for all runners or could indicate how participants usually feel on the eve of a road race.

Listening to music in training or competitions was quite prevalent in our sample. Despite this high prevalence, the possible ergogenic effect of music is still a controversial issue in the scientific literature. Previous studies have shown that music has improved psychological skills, such as attention (Terry and Karageorghis, 2006), state of animus (Terry and Karageorghis, 2006) and humour (Karageorghis and Terry, 2008). A cross experimental study compared running time with and without musical listening (Clark et al., 2018). As results, there was no statistically significant difference between experimental conditions, but music seems to have a positive effect in reducing perception of effort (Clark et al., 2018). It is common that athletes listen to music before sports practice, but there is no evidence that this provides an ergogenic effect (Smirmaul, 2017). Therefore, it is possible that music makes the running practice more pleasurable and aids in the runner's adherence, which can be studied in future research.

The most consumed dietary supplement was protein, and the main motivations were the increase of competitiveness and health. In resistance training, a recent metaanalysis has shown that protein supplementation increases muscle mass and strength in the one maximum repetition test (Morton et al., 2018). Despite these results, protein consumption higher than $1.62 \mathrm{~g} / \mathrm{kg} /$ day does not seem to present additional gains in physical performance, there being an ideal level for its daily consumption (Morton et al., 2018). In relation to endurance, protein supplementation also seems promising. In this sense, a double-blind randomized clinical trial compared the effects of whey protein versus maltodextrin (placebo) on the performance of 12 university athletes (Huang et al., 2017). After 4 weeks of supplementation, there was a difference for the 12-minute run/walk test, where participants who consumed whey protein obtained longer distances compared to the placebo group (Huang et al., 2017). In our study, we found no association between consumption of dietary supplement and running performance. We believe that this result may be due to the absence of nutritional follow-up, inadequate choice of the type of supplement and inadequate intake of nutrients in relation to physiological demands. We have the hypothesis that consuming dietary supplements without nutritional follow-up does not offer a sporting advantage.

\subsection{Mental training and performance in road races}

Previous studies demonstrated the positive effect of mental training in different sports (Bales and Bales, 2012; Bühlmayer et al., 2017; Dolan et al., 2011; Houston et al., 2011). Mental techniques are known by elite athletes and are usually well accepted when included in training programs (Gould and Maynard, 2009). In competitions, relaxation and breathing techniques, visualization and biofeedback can improve mental abilities, favouring sport performance (Keilani et al., 2016). In our study, the runners who did 
mental training had approximately double of chances of better performance compared to the participants who did not. This result was maintained despite the adjustments by different confounders. This is a promising result, but we should be careful in this generalization, because there was low prevalence of mental training and psychological follow-up in our sample. Despite this, the few participants who received psychological support evaluated this follow-up quite satisfactorily. Associating this information with the possible effect of mental training on the performance of recreational runners, psychological support seems to be fundamental for those who want to evolve in road races.

\section{Limitations}

We did not investigate the dosage of dietary supplementation, if this consumption was by recommendation of a nutritionist, and which mental techniques these runners used. We believe that the anxiety could be evaluated together with the installation of the chip, which would provide a more accurate estimate. Despite these limitations, our study corroborates the scientific literature and provides new insights about the importance of nutritional and psychological follow-up for runners.

\section{Conclusion}

The practice of road races seems to promote well-being and quality of life, besides helping to reduce stress. We hypothesize that dietary supplementation without nutritional follow-up does not offer a competitive advantage and that mental training can favour the performance of runners. Finally, we also present a strategy for the use of running events for scientific research, with possible directions for future studies.

\section{Acknowledgements}

VNS is supported by Brazilian fellowship from Coordenação de Aperfeiçoamento de Pessoal de Nível Superior (CAPES) Processo nº 88882.435438/2019-01.

\section{Disclosure statement}

The authors declare no conflict of interest.

\section{Authors' contributions}

VNS conceptualized the study and performed the statistical analysis. GKFC contributed to conceptualizing the study. JVVS contributed to methodological design. PTF guided the authors of the study. All authors contributed to drafting and critical review the manuscript. 


\section{References}

Andersen JJ, 2020. The State of Running 2019. https://runrepeat.com/state-of-running. Accessed 10 September 2020.

Baker LB, Rollo I, Stein KW, Jeukendrup AE, 2015. Acute Effects of Carbohydrate Supplementation on Intermittent Sports Performance. Nutrients, 7(7): 5733-5763, doi:10.3390/nu7075249

Bales J, Bales K, 2012. Triathlon: how to mentally prepare for the big race. Sports Medicine and Arthroscopy Review, 20(4): 217-219, doi:10.1097/JSA.0b013e31825efdc5

Baltazar-Martins G, Brito de Souza D, Aguilar-Navarro M, Muñoz-Guerra J, Plata MDM, Del Coso J, 2019. Prevalence and patterns of dietary supplement use in elite Spanish athletes. Journal of the International Society of Sports Nutrition, 16(1): 30, doi:10.1186/s12970-019-0296-5

Bar-Eli M, Blumenstein B, 2004. Performance enhancement in swimming: the effect of mental training with biofeedback. Journal of Science and Medicine in Sport, 7(4): 454-464, doi:10.1016/s1440-2440(04)80264-0

Bühlmayer L, Birrer D, Röthlin P, Faude O, Donath L, 2017. Effects of Mindfulness Practice on Performance-Relevant Parameters and Performance Outcomes in Sports: A Meta-Analytical Review. Sports medicine, 47(11): 2309-2321, doi:10.1007/s40279-017-0752-9

Cassiano ADN, Silva TSD, Nascimento CQD, Wanderley EM, Prado ES, Santos TMM, Mello CS, Barros-Neto JA, 2020. Effects of physical exercise on cardiovascular risk and quality of life in hypertensive elderly people. Ciência \& Saúde Coletiva, 25(6): 2203-2212, doi:10.1590/1413-81232020256.27832018

Clark JC, Baghurst T, Redus BS, 2018. Self-Selected Motivational Music on the Performance and Perceived Exertion of Runners. The Journal of Strength \& Conditioning Research, doi:10.1519/jsc.0000000000002984

Dauwan M, Begemann MJH, Slot MIE, Lee EHM, Scheltens P, Sommer IEC, 2019. Physical exercise improves quality of life, depressive symptoms, and cognition across chronic brain disorders: a transdiagnostic systematic review and metaanalysis of randomized controlled trials. Journal of Neurology, doi:10.1007/s00415-019-09493-9

Dolan SH, Houston M, Martin SB, 2011. Survey results of the training, nutrition, and mental preparation of triathletes: practical implications of findings. Journal of Sports Sciences, 29(10): 1019-1028, doi:10.1080/02640414.2011.574718

Foddy W, 1994. Constructing questions for interviews and questionnaires: Theory and practice in social research. Cambridge university press, doi:10.1017/CBO9780511518201

Gould D, Maynard I, 2009. Psychological preparation for the Olympic Games. Journal of Sports Sciences, 27(13): 1393-1408, doi:10.1080/02640410903081845 
Houston M, Dolan S, Martin S, 2011. The impact of physical, nutritional, and mental preparation on triathlon performance. Journal of Sports Medicine and Physical Fitness, 51(4): 583-594.

Huang WC, Chang YC, Chen YM, Hsu YJ, Huang CC, Kan NW, Chen SS, 2017. Whey Protein Improves Marathon-Induced Injury and Exercise Performance in Elite Track Runners. International journal of medical sciences, 14(7): 648-654, doi:10.7150/ijms.19584

Karageorghis CI, Terry PC, 2008. The psychological, psychophysical and ergogenic effects of music in sport: a review and synthesis, doi:10.4324/9780203887974_chapter_1

Keilani M, Hasenöhrl T, Gartner I, Krall C, Fürnhammer J, Cenik F, Crevenna R, 2016. Use of mental techniques for competition and recovery in professional athletes. Wien Klin Wochenschr, 128(9-10): 315-319, doi:10.1007/s00508-016-0969-x

Lentjes MAH, 2019. The balance between food and dietary supplements in the general population. Proceedings of the Nutrition Society, 78(1): 97-109, doi:10.1017/S0029665118002525

Ministerio de Educación, Cultura y Deporte, 2015. Encuesta de hábitos deportivos en españa 2015. https://www.culturaydeporte.gob.es/dam/jcr:aa63cca9-31a5-47ce8ac2-

105215f64d9f/Encuesta de Habitos Deportivos 2015 Sintesis de Resultados.pd f. Accessed 7 October 2020.

Morton RW, Murphy KT, McKellar SR, Schoenfeld BJ, Henselmans M, Helms E, Aragon AA, Devries MC, Banfield L, Krieger JW, Phillips SM, 2018. A systematic review, meta-analysis and meta-regression of the effect of protein supplementation on resistance training-induced gains in muscle mass and strength in healthy adults. British Journal of Sports Medicine, 52(6): 376-384, doi:10.1136/bjsports-2017097608

Salgado JV, Lollo PC, Amaya-Farfan J, Chacon-Mikahil MP, 2014. Dietary supplement usage and motivation in Brazilian road runners. Journal of the International Society of Sports Nutrition, 11: 41, doi:10.1186/s12970-014-0041-z

Smirmaul BP, 2017. Effect of pre-task music on sports or exercise performance. Journal of Sports Medicine and Physical Fitness, 57(7-8): 976-984. doi:10.23736/s00224707.16.06411-2

Southward K, Rutherfurd-Markwick KJ, Ali A, 2018. The Effect of Acute Caffeine Ingestion on Endurance Performance: A Systematic Review and Meta-Analysis. Sports Medicine, 48(8): 1913-1928, doi:10.1007/s40279-018-0939-8

Strava, 2018. O Ano Esportivo no Brasil. https://blog.strava.com/pb/press/2018-year-insport/. Accessed 1 October 2020.

Terry PC, Karageorghis CI, 2006. Psychophysical effects of music in sport and exercise: An update on theory, research and application, Australian Psychological Society, 415-419. $\quad$ https://www.semanticscholar.org/paper/Psychophysical-effects-ofmusic-in-sport-and-an-on-Terry- 
Vinícius Nagy Soares, Gabriela Kaiser Fullin Castanho, José Vitor Vieira Salgado, Paula Teixeira Fernandes ASSOCIATION OF DIETARY SUPPLEMENTS AND MENTAL TRAINING

WITH PERFORMANCE IN ROAD RACES

Karageorghis/fd6f71762d68e2d8de914c865ab83789f263b056. Accessed 15 October 2020.

Creative Commons licensing terms

Authors will retain the copyright of their published articles agreeing that a Creative Commons Attribution 4.0 International License (CC BY 4.0) terms will be applied to their work. Under the terms of this license, no permission is required from the author(s) or publisher for members of the community to copy, distribute, transmit or adapt the article content, providing a proper, prominent and unambiguous attribution to the authors in a manner that makes clear that the materials are being reused under permission of a Creative Commons License. Views, opinions and conclusions expressed in this research article are views, opinions and conclusions of the author(s). Open Access Publishing Group and European Journal of Physical Education and Sport Science shall not be responsible or answerable for any loss, damage or liability caused in relation to/arising out of conflict of interests, copyright violations and inappropriate or inaccurate use of any kind content related or integrated on the research work. All the published works are meeting the Open Access Publishing requirements and can be freely accessed, shared, modified, distributed and used in educational, commercial and non-commercial purposes under a Creative Commons attribution 4.0 International License (CC BY 4.0). 